\title{
Game Behavior Analysis of Project Bidding Period Under Agent-Construction System
}

\author{
Wan-Ling ZOU ${ }^{1, a,{ }^{*},}$ Shan WU ${ }^{2, b}$ \\ ${ }^{1,2}$ Xihua University of Architecture and Civil Engineering Sichuan Chengdu China, 610039 \\ a1274640422@qq.com, b25816818@qq.com \\ ${ }^{*}$ Corresponding author
}

Keywords: Agent-construction system, Rent-seeking behavior, Game-playing behavior.

\begin{abstract}
Severe rent-seeking behaviors are now very common in project bidding period under agent-construction system. The cooperation which happened in project bidding period between the biding side and the agent side harms the construction owner's benefits. Aiming at figuring out the game behaviors in project bidding period under agent-construction system, this paper analyzes the game behaviors among construction owner, agent side and rent-seeking side and the relationship among the three sides(the principal agent relationship between the project owner and construction agency, the supervision and publishment relationship among the project owner, construction agency and rent-seeking side, the cooperation and game-playing between construction agency and rent-seeking side) and the game-playing balance among three sides. Through studying that, the rent-seeking behaviors in project bidding period under agent-construction system can be reduced or prevented.
\end{abstract}

\section{Introduction}

In the period of project bidding based on agent-construction system, in order to exclude other bidders to obtain construction project and gain higher benefits from the contract price than one which sign in the normal way, the rent-seeking side often rents from the construction agency. In fact, the construction agency is not the final beneficial owner; they often accept the rent-seeking's request and cooperate with them so as to maximize the agency self-interest. For example, the agent-construction side reveals the bidding information to the rent-seeking one or assists the rent-seeking side in replacing the bidding documents and changing the bidding price. In the meanwhile, the rent-seeking side and the construction agency side agree to lower or raise the price at the time of bidding to help the rent-seeking side obtain the construction project and then the construction agency will receive additional compensation from the beneficiary.

This paper analyzes the relationship and the game-playing balance among the construction owner, the agent side and the rent-seeking side in bidding period. Through studying that, the rent-seeking behaviors in project bidding period under agent-construction system can be reduced or prevented.

\section{The Game-Playing Behaviors and Relationships among Three Sides}

In the period of project biding, the rent-seeking side will give the construction agent money privately or promise them to get a portion of extra interests. There are four kinds of circumstances which could happen.

At first, if the project agent does not accept the rent-seeking side's request and keeps the faith, the seeking rent side pays the money while they don't get extra benefits and the construction agency can only get money which they should get.

Secondly, if the project agent accepts the rent-seeking side's behaviors and cooperates with each other, the seeking rent side will get extra money and the construction agency can also get their salaries and extra money through rent seek. As a result, the benefits of project owner have been damaged by these behaviors. 
Thirdly, if the project owner takes personal supervision and finds the rent-seeking behaviors in the period of bidding, the project owner will punish the agent and the rent-seeking one through confiscating additional benefits and charging them a certain amount of fees.

At last, if the project owner does not supervise, they will pay more money than the contract price as a consequence of misconduct.

In conclusion, the project owner not merely has the principal-agent relation with the agent-construction side but also has right to supervise and punish the agent and the rent-seeking one. The relation among three sides is shown in Figure1.

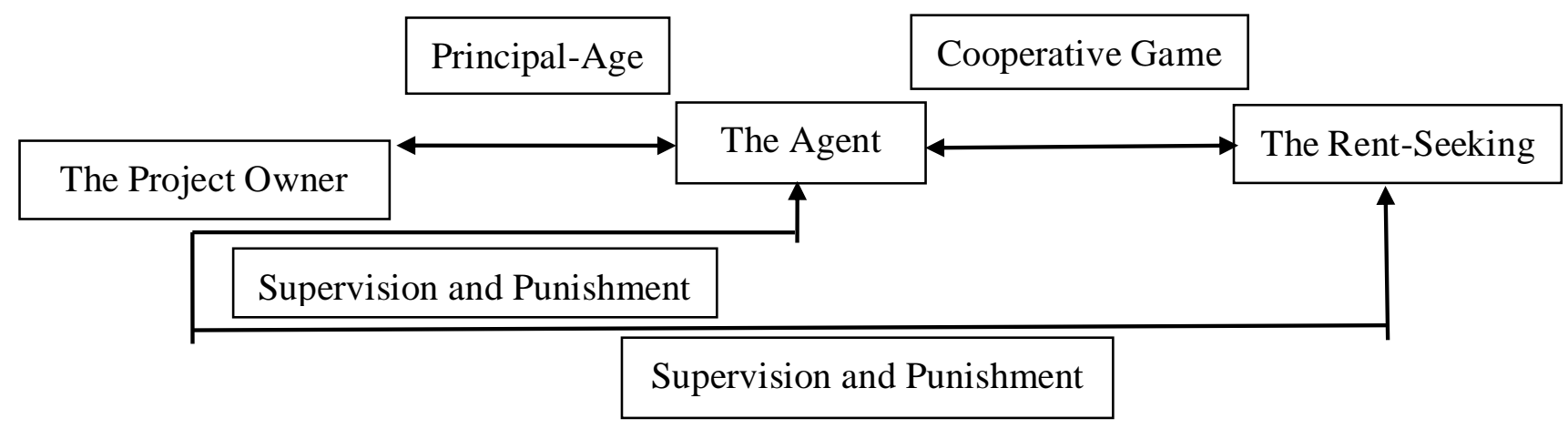

FIG. 1 The Tripartite Interest Relationship

\section{Game Conditions and Equilibrium among Three Sides}

\section{Condition Analysis of Game Model}

Game-behaviors participants are the project owner, the agent and the rent-seeking side. The game strategies of the owner is supervision or non-supervision, the strategies of construction agency is to accept or not to accept the rent-seeking request and the strategies of rent-seeking side is rent-seeking or not rent-seeking. The following will introduce that game participants will get different paybacks by using different strategies.

(1)Game participants are the project owner, the agent and the rent-seeking side, the relationships between the project owner and the other two sides can be described as non-cooperative game. There is some probability which can be marked as $\theta$ that the project owner supervises the rent-seeking behaviors between the agent and the rent-seeking side.

(2)The successful probability of the project owner supervising is $\partial$ and the probability of the rent-seeking doing the rent-seeking behaviors is $\beta$.

(3)In period of bidding, the final contract price can be set to $A$ when the rent-seeking behaviors do not happen, the agent agrees to give the rent-seeking side the contract price which is set as $A_{1}$ through the rent-seeking, and the cost is set to $M$ which is paid by the rent-seeking side through rent-seeking $M$ contains two parts, one is $M_{1}$ the rent-seeking side gives to the agency from the excess earnings or in private, the other is $M_{2}$ which is the fine when the rent-seeking behaviors is discovered by the owner), if the rent-seeking side has a rent-seeking behavior but the project owner does not supervise this behavior, the earnings of the agent, the rent-seeking side and the project owner can be calculated respectively as: $M_{1}\left(M_{1}=M, M_{2}=0\right), A_{1}-A-M_{1},-\left(A_{1}-A\right)$. The profit of the agent, the rent-seeking side and the project owner can be calculated as $M_{1}\left(M_{1}=M, M_{2}=0\right), A_{1}-A-M_{1}$ and $-\left(A_{1}-A\right)$ respectively.

(4)The cost which is produced by doing the supervision can be set to $Z$. If the owner supervises unsuccessfully and the rent-seeking behaviors still exist, the earnings of the agent, the rent-seeking side and the project owner can be calculated respectively as: $M_{1}\left(M_{1}=M, M_{2}=0\right), A_{1}-A-M_{1},-\left(A_{1}-A\right)-Z$. 
(5)The cost which is produced by doing the supervision can be set to $Z$. If the owner supervises successfully, the punishment to the agency is confiscated the extra benefits $M_{1}\left(M_{1}\right.$ is also the money the rent-seeking side gives to the agency from the excess earnings or in private), which must be taken back and the agency should pay the fine which is $m$ times as big as $M_{1}$, at meantime, the fine to the owner is $n$ times as big as $M_{1}$ and the punishment to the rent-seeking side is not only taking the extra money $A_{1}-A$ back but also fine $i$ times as big as $A_{1}-A$, the earnings of the agent, the rent-seeking side and the project owner can be calculated respectively as: $-n M_{1}-m M_{1}$, $-(i+1)\left(A_{1}-A\right)-M_{1}\left(M_{2}=i\left(A_{1}-A\right)\right), M_{1}(m+n+1)+i\left(A_{1}-A\right)-Z$.

(6)If the owner supervises successfully and there is no rent-seeking behaviors, the earnings of the agent, the rent-seeking side and the project owner can be calculated respectively as:0,0-Z . If there is no rent-seeking behaviors and the owner does not supervise, the earnings of the agent, the rent-seeking side and the project owner can be calculated respectively as:0,0,0.

\section{The Model of Game and Nash Equilibrium}

According to the assumptions of the tripartite game, the profit model of the tripartite game is shown in table1.

Tab.1 The Profit Model of The Tripartite Game

\begin{tabular}{|l|l|l|l|}
\hline \multirow{2}{*}{$\begin{array}{l}\text { Owner } \\
\text { The agent } \\
\text { and The Rent-Seeking side }\end{array}$} & Succeed $\left.{ }^{\partial}\right)$ & Fair $(1-\partial)$ & $\begin{array}{l}\text { No } \\
\text { Supervision( } 1-\theta \\
\end{array}$ \\
\cline { 2 - 4 } & $-n M_{1}-m M_{1}$ & $M_{1}$ & $M_{1}$ \\
& $-(i+1)\left(A_{1}-A\right)-M_{1}$ & $A_{1}-A-M_{1}$ & $A_{1}-A-M_{1}$ \\
Rent-Seeking $(\beta)$ & $M_{1}(m+n+1)+i\left(A_{1}-A\right)$ & $-\left(A_{1}-A\right)-Z$ & $-\left(A_{1}-A\right)$ \\
& & & \\
\hline \multirow{3}{*}{ No Rent-Seeking $(1-\beta)$} & 0 & 0 & 0 \\
& 0 & 0 & 0 \\
\hline
\end{tabular}

Attention:

(1)The first row of the table above represents the benefit of the construction agent in rent-seeking behaviors.

(2)The second row of the table above represents the profit of the rent-seeking side.

(3)The third row of the table above represents the profit of the project owner.

According to the condition of the tripartite game, under the circumstances that the probability of rent-seeking behavior is $\beta$, the expected revenue of the project owner supervising or not can be calculated respectively as:

$$
\begin{aligned}
& \left.E_{1}=\beta\left\{\partial\left[M_{1}(m+n+1)+i\left(A_{1}-A\right)-Z\right]+(1-\partial)\left[-\left(A_{1}-A\right)-Z\right]\right\}+(1-\beta)[\partial(-Z)+(1-\partial)(-Z)]\right\} \\
& E_{2}=\beta\left[-\left(A_{1}-A\right)\right]
\end{aligned}
$$

When $E_{1}=E_{2}$, the best probability of the construction agent and the rent-seeking side who decide whether to do rent-seeking behavior or not is:

$$
\beta=Z / \partial\left[M_{1}(m+n+1)+(i+1)\left(A_{1}-A\right)\right] .
$$


When the project owner supervises the agent at a certain probability of $\theta$, the expected earnings that the rent-seeking one does the behavior or not is:

$$
\begin{aligned}
& E_{3}=\theta\left[\partial\left(-m M_{1}-n M_{1}\right)+(1-\partial) M_{1}\right]+(1-\theta) M_{1} \\
& E_{4}=0
\end{aligned}
$$

When $E_{3}=E_{4}$, the best probability that the project owner supervises when the construction agent is in a balanced game is:

$$
\theta=1 / \partial(m+n+1)
$$

When the project owner supervises the rent-seeking side at a certain probability of $\theta$, the expected earnings that the rent-seeking one does the behavior or not is:

$$
\begin{aligned}
& E_{5}=\theta\left[\partial\left(-(i+1)\left(A_{1}-A\right)-M_{1}\right)+(1-\partial)\left(A_{1}-A-M_{1}\right)\right]+(1-\theta)\left(A_{1}-A-M_{1}\right) \\
& E_{6}=0
\end{aligned}
$$

When $E_{5}=E_{6}$, the best probability that the project owner supervises when the rent-seeking side is in a balanced game is:

$$
\theta=\left(A_{1}-A-M\right) / \partial(i+2)\left(A_{1}-A\right)
$$

In conclusion, the game mixed strategy Nash equilibrium solution is:

$$
\begin{aligned}
& \left\{\beta^{*}, \theta_{1}^{*}\right\}=\left\{Z / \partial\left[M(m+n+1)+(i+1)\left(A_{1}-A\right)\right], 1 / \partial(m+n+1)\right\} \\
& \left\{\beta^{*}, \theta_{2}^{*}\right\}=\left\{Z / \partial\left[M(m+n+1)+(i+1)\left(A_{1}-A\right)\right],\left(A_{1}-A-M\right) / \partial(i+2)\left(A_{1}-A\right)\right\}
\end{aligned}
$$

\section{The Meaning of The Tripartite Game Equilibrium}

(1)In the tripartite game model, through the mixed strategy Nash equilibrium, we can see that the construction agent and rent-seeking side carry out the activities in the probability of $\beta^{*}$ and acquire additional benefits. In the first case, if the two sides of rent-seeking probability is $\beta>\beta^{*}$, the best choice for the construction owner is to strengthen the supervision of rent-seeking behaviors. In the second case, if the two sides of rent-seeking probability is $\beta<\beta^{*}$, the owner does not have to supervise the rent-seeking activities. In the last case, if the two sides of rent-seeking probability is $\beta=\beta^{*}$, the owner can randomly select to supervise or not.

(2)The probability of rent-seeking activities $\beta^{*}$ is influenced by the several variables, namely $Z 、 M 、 n 、 m 、 A_{1}, A 、 \partial 、 i$. In these variables, $M 、 A_{1}, A$ are unable to control by the project owner, which can be regarded as constant in this model. The owners can only influence rent-seeking probability by controlling $Z 、 m 、 n 、 \partial 、 i$.Their relationship is that $\beta^{*}$ has a direct proportion with $Z$ and is inversely proportion to $m 、 n 、 \partial 、 i$. As a result, the project owner can 
reduce the probability of rent-seeking through the methods such as decreasing the cost of supervision cost and increasing penalties $m 、 n 、 i$ and improving the probability of supervision success etc.

If we will give top priority to the interests of the agent, the probability of the project owner who decides whether to supervise or not is $\theta_{1}^{*}=1 / \partial(m+n+1)$. In the first place, if the supervision probability is $\theta>\theta_{1}^{*}$, which means improving the probability of success oversight which can make the fine far exceeds the income brought by accepting rent-seeking behavior for the construction agent, the agent is responsible for the owner and does what they should do.

In the second place, if the supervision probability is $\theta<\theta_{1}^{*}$, which means the amercement brought by the rent-seeking activity less than the profit, the agent may accept the request of rent-seeking from the rent-seeking side.

In the third place, if the supervision probability is $\theta=\theta_{1}^{*}$, the agent can make choices at random.

Focus on the inverse relationships between $\theta_{1}^{*}$ and $m 、 n 、 \partial$,the project owner can reduce the probability of rent-seeking through the methods such as decreasing the cost of supervision cost and increasing penalties $m 、 n 、 i$ and improving the probability of supervision success which can make the punishment to the agent outweighs the benefits from the rent-seeking behavior etc.

On the contrast, if we give top priority to the interests of the agent, the probability of the project owner who decide whether to supervise or not is $\theta_{2}^{*}=\left(A_{1}-A-M\right) / \partial(i+2)\left(A_{1}-A\right)$.In the first case, if the supervision probability by the owner is $\theta<\theta_{2}^{*}$, which means the punishment to the rent-seeking side is less than the benefits brought by the rent-seeking behavior, the result is that the rent-seeking side can carry out the behavior.

In the second case, if the supervision probability is $\theta>\theta_{2}^{*}$, which means to increase the penalties for the rent-seeking sides so that the punishment to the rent-seeking side outweighs the benefits of rent-seeking behaviors, as a result, the rent-seeking side will not do the behaviors.

The variable named as $\theta_{2}^{*}$ is mainly influenced by $M 、 A_{1} 、 A 、 \partial 、 i$, however, the variable of $M 、 A_{1} 、 A_{\text {can }}$ be regarded as constant. Only in this way that the project owner increases the successful probability of supervision and the penalties for the rent-seeking sides which can make the punishment to the rent-seeking side outweighs the benefits brought by the rent-seeking behavior, will the rent-seeking behaviors be reduced or prevented.

\section{Conclusion}

Based on game mixed strategy Nash equilibrium solution $\left\{\beta^{*} 、 \theta_{1}^{*}\right\}$ and $\left\{\beta^{*} 、 \theta_{2}^{*}\right\}$, it is concluded that: to prevent rent-seeking behavior which may occur in the agent-construction system, the probability of success $\partial$ should be strengthened and the punishment of both sides should be laid down through the contract. No matter whether the agent's interest or the rent-seeking one's interest should go to the first place,the project owner should first of all increase $\partial$ under a certain cost and cooperate with $m 、 n 、 i$. In that case, to the owner and rent-seeking one, the punishment will be more than the benefits if they were rent-seeking which obeys the contract. Therefore, this is an effective way to reduce and prevent rent-seeking behaviors.

\section{Acknowledgement}

The Scientific and Technological Innovation Project of Ministry of Housing and Urban-Rural Development(Project Number:2013-R1-4):Study on the Effect of Building Energy Saving Technology and Evaluation System. 
Project Supported by the Key Laboratory of Sichuan Province Open Research Fund(Project Number:szjj2012-033):Green Building and Energy Conservation.

Zou Wanling (1991- ), female, Neijiang Sichuan China. mainly engaged in research of Engineering Project Management and the Construction.

Wu Shan (1989- ), female, Suining Sichuan China. mainly engaged in research of Engineering Project Management and the Construction.

\section{References}

[1] He Wei. Rent Seeking Economics[M].Cheng Du. The Economics Press of Southwestern University of Finance.1999.

[2] China Association of Engineering Consultants. Introduction to Engineering Consultants[M]. Intellectual Property Publishing House.2003.

[3] Cheng Hu. Engineering Project Management [M]. Architecture Building Press.Beijing.2002.

[4] Zhang Weiying. Game Theory and Information Economics[M].The People's Publishing House of Shanghai,.Shanghai.2002.

[5] Weikbull J W. Evolutionary Game Theory,MIT,1995.

[6] Fudenberg D. Tirole J.Game Theory,MIT,1995.

[7] Kreps D. Game Theory and Economic Modeling,Oxford University Press, 1990.

[8] GIB. Product Zent rales Project Controlling, 1997.

[9] Geprge K Ritz. Total Construction Project Controlling Mc-Graw- Hill, Inc, 1994.

[10] Roy Gardner. Games for Business and Economics, John Wiley \&Sons, Inc. 1995. 